\title{
0 teste de glutaraldeído e sua aplicação na claudicação de bovinos de leite
}

Caroline Fernanda da Rosa, Bruna Becker Gaveliky, Caroline Tomasi Bortoleto, Juliane Scharlau Xavier, Renata Luisa Soares, Maria Luisa de Andrade Carvalho, Ligia Valéria Nascimento, Rudiger Daniel Ollhoff'

Programa de Pós-Graduação em Ciência Animal, Pontifícia Universidade Católica do Paraná (PUCPR), Curitiba, PR, Brasil

*Autor correspondente

e-mail: ollhoff@gmail.com

\section{Resumo}

A claudicação é atualmente uma das maiores preocupações de saúde nas criações de bovinos de leite, com consequências diretas sobre o bem estar e a produtividade do rebanho afetado. Por outro lado, para os veterinários de campo buiatras, existem poucos exames complementares que podem ser usados "ao lado da vaca" com a finalidade de auxiliar em diagnósticos. 0 teste de glutaraldeído (TG) é um teste capaz de avaliar a ocorrência de um processo inflamatório, por reagir com o fibrinogênio e as imunoglobulinas do sangue total do bovino. É medido o tempo que o sangue leva para coagular após entrar em contato com o líquido teste, categorizado em TG1 (< 3 minutos), TG2 ( $3<6$ minutos), TG3 ( $6<15$ minutos) e TG4 ( > 15 minutos). Objetivou-se verificar se o TG possui correlação com o grau de claudicação em um rebanho de bovinos de leite. Foram utilizadas 69 vacas da raça Holandesa de uma propriedade leiteira em sistema de criação em estabulação livre sobre ripado de concreto de uma propriedade no Paraná. Colheu-se sangue de todas as vacas via punção coccígea para o TG e aplicou-se um escore de locomoção (1 a 5) no caminho entre o estábulo e a ordenha. Verificou-se que somente 26 vacas $(37,7 \%)$ não apresentavam claudicação (escore 1). A maioria ( $\mathrm{N}=24 ; 34,8 \%$ ) das claudicantes a apresentava em grau leve (2), com 16 vacas com escore 3, duas com escore 4 e uma com escore 5. Observou-se vacas com intenso processo inflamatório (TG1) em $30,4 \%$ dos testes, distribuindo-se as demais avaliações nas seguintes frequências: 26,1 \% TG2, $42 \%$ TG3 e 1,4\% TG4. Após teste de normalidade, aplicou-se a correlação de Pearson obtendo um valor de - 0,33. Existe, portanto, uma correlação de média intensidade negativa. Como as vacas de leite em alta produção estão sujeitos a uma série de outros processos inflamatórios (exemplos: mastites, catarros genitais) e não houve preocupação em excluir-se estes animais, não se esperava uma correlação muito intensa. Este valor possivelmente pode ser melhorado aplicando-se um processo de seleção mais criterioso. Algumas 
enfermidades podais ou alterações de postura, podem não induzir a um processo inflamatório muito intenso apesar de serem detectados pela avaliação por inspeção da locomoção. 0 teste foi originalmente desenvolvido para avaliar processos inflamatórios profundos e que podem passar desapercebidos, como os relacionados a reticulites e peritonites. Deve-se aprofundar ainda os estudos sobre o TG para avaliar sua possível contribuição para a melhor compreensão dos problemas locomotores. 